Utah State University

DigitalCommons@USU

Behavioral Education for Human, Animal,

Vegetation, and Ecosystem Management

(BEHAVE)

2005

\title{
Flaws in Orr's Laws (and the Paradigm that Produced Them): An Abbreviated Response
}

Nicole Haynes McCoy

Utah State University

Sheldon Atwood

Utah State University

Follow this and additional works at: https://digitalcommons.usu.edu/behave

Part of the Environmental Sciences Commons

\section{Recommended Citation}

McCOY, N. H., \& Atwood, S. (2005). Flaws in Orr's Laws (and the Paradigm that Produced Them): an Abbreviated Response. Conservation Biology, 19(4), 1318-1320. doi:10.1111/j.1523-1739.2005.00224.x

This Article is brought to you for free and open access by the Conferences and Events at DigitalCommons@USU. It has been accepted for inclusion in Behavioral Education for Human, Animal, Vegetation, and Ecosystem Management (BEHAVE) by an authorized administrator of DigitalCommons@USU. For more information, please contact digitalcommons@usu.edu. 


\title{
Flaws in Orr's Laws (and the Paradigm that Produced Them): an Abbreviated Response
}

\author{
NICOLE HAYNES MCCOY* AND SHELDON ATWOOD $†$ \\ *Department of Environment and Society, Utah State University, 5215 Old Main Hill, Logan, UT 84322-5215, U.S.A., \\ email nicole.mccoy@usu.edu \\ †Forestry, Wildlife, and Range Sciences Department, Utah State University, 5230 Old Main Hill, Logan, UT 84322-5230, U.S.A.
}

Conservation of biological diversity is often hampered by ignorance and short-sightedness. Yet knowledge is not enough; biology illuminates ecological relationships, but it alone cannot conserve ecosystems. Therefore, we agree that there is no higher priority for conservation biologists than to improve their understanding of economics (Orr 2004, Law 1). Unfortunately, from many of his comments and the tenor of subsequent responses (Hayes 2004; Vitek 2004; Lovejoy 2004), it is evident that economics and, more important, parallels between ecology and economics are misunderstood, implying the two disciplines are more different than they are and that knowledge of economics is primarily needed to enhance the appeal of ecological insight. We offer comments intended to (1) correct misunderstandings about the parallel sciences of ecology and economics; (2) present a broader perspective on efficiency, selfishness, ecological bubbles, and conditions for growth; and (3) discuss the appropriate role of science in addressing natural resource problems. Efforts to maintain ecological integrity will benefit when we abandon the erroneous assumption that ignorance and selfishness per se cause environmental problems.

\section{Ecology Is Economics}

Economics is generically defined as the study of scarce resource allocation, yet it is predominantly associated with human behavior and monetary transfers. Thus, many biologists consider economic issues peripheral to ecology, viewing them as human constructs with potentially disastrous consequences for organisms or ecosystems (Law 1). Like ecology, economics is all about who gets what, when, how, and how much. Economic theory has been

Paper submitted February 2, 2005; revised manuscript accepted March 29, 2005. successfully applied to numerous ecological issues and businesses must conform to ecological principles to survive. Nevertheless, few scientists appreciate the vast economic landscape within ecosystems or realize that ecologists, biologists, and economists study the same phenomena, albeit using seemingly proprietary terminology.

Resource scarcity is inherent in both economic and ecological problems (Law 2). Both disciplines study how biological organisms, including people, allocate available resources to their most highly valued uses and assess which contexts encourage more efficient and effective behaviors. Ecologists tend to support allowing ecological processes to proceed without inordinate intervention and many economists agree. The free market environment championed by neoclassical economists is simply a context-dependent ecological analog of nature. Diversity, choice, and evolution are important ecosystem characteristics for all creatures, including humans. Furthermore, there is nothing about the free market that precludes the provision of any ecosystem good or service, including conservation and environmental protection. Unfortunately, we just cannot afford to have as much of everything as we might want.

When conservation or environmental protection doesn't occur, it means that either there was another, higher valued use of the resource or there is a distortion that results in lower valued uses being selected (Law 3). If the former occurs, it's not bad, selfish, or immoral, but simply a reflection of societal or individual preferences. If the latter is the case, it indicates structural problems in attributing benefits to those that bear the cost of a transaction. This problem is a common occurrence in the natural world even though evolutionary processes act to minimize the negative impact of these relationships over time. Some conservationists have forgotten nature's ability to adapt to an ever-changing environment and propose inappropriate interventions on behalf of individuals or populations at the expense of communities or systems. 


\section{Efficiency Isn't Evil}

Maximizing efficiency does not create inefficiency in the way Orr (2004; Law 1, Corollary 2) describes. Efficiency can be loosely defined as making the best possible use of scarce resources, in other words, minimizing costs and reducing waste. Unless the cumulative financial, ecological, social, and individual benefits of these activities are compared against their costs, there is no way to determine whether or not they are efficient. Efficiency doesn't imply fairness and cannot claim the purpose of prosperity, security, benevolence, or reputation as argued by Orr (2004). It is simply a ratio that indicates whether resources are allocated to their most highly valued use within a given context. Employed correctly, efficiency would see that clean water goes to the thirsty before it is used on the lawn. As markets and the economy as a whole become more efficient, fewer resources are wasted. We suspect that Dr. Orr's unstated comment may have been that what is efficient for the individual can be inefficient for a greater society. This is true, tending to occur when resources exhibit public goods characteristics that can lead to "tragedy of the commons" scenarios in which long-term social welfare is reduced by individuals seeking to maximize short-term self-interest. Nonetheless, individuals can be encouraged to act in society's interest if the appropriate contingencies are created.

\section{Selfishness and Self-Interest are Ecological Synonyms}

Self-interest is an evolutionary necessity; survival demands it (Law 1, Corollary 1). Few behaviors do not involve self-interest. Even altruism is a form of cooperative strategy that is clearly self-interest viewed from one of two alternative perspectives. People are generally either internally or externally rewarded for being "selfless." For individuals that value the reward, it is a good purchased with the behavior. When the community is the organism of focus, cooperative strategies contribute to the survival of the larger entity, often enhancing the viability of individuals and making self-interest clearly evident when individuals identify themselves as constituents of broader entities. On the other hand, selfishness is a strictly subjective term commonly interpreted as a disregard for others. From this perspective, the wolf and its prey are both selfish, yet nature encourages enough killing to efficiently meet needs-not wanton destruction. Therefore, holistically speaking, absolute selfishness absent immediate self-interest has no ecological or economic precedent.

Self-interested liberals may be trying to figure out how to limit human appetites (Orr 2004; Law 2), but unless this "limiting" is seen by the individual as voluntary and is reflected as a change in preferences, such efforts will fail. By definition, involuntary limits infringe on freedom. Apparently some among us are willing to elevate themselves over the rest of the world's populace to decide whose freedom should be limited and how much to limit it. Lest this responsibility be entrusted to special interests or the state, we remind everyone that we have tried economic systems that intensively regulate human behavior-they are commonly referred to as socialism and communism.

\section{Ecological and Economic Bubbles are Ephemeral}

Hayes (2004) states that natural resource consumption should not end up in the income column because it is a loss and argues the existence of an ecological bubble similar to economic bubbles. When a stock resource is depleted, a cost commensurate with the loss of capital is incurred, but benefits are also created because there is a conversion to a higher valued product. Capital may change form in the process but change is not necessarily entropic to an ecosystem. Waste to one organism is very often a resource to another. All types of wealth are subject to re-evaluation and natural capital is no different from any other currency in this regard. With a few exceptions, oil was worthless high entropy waste 150 years ago, and low entropy potential did not exist. Now it is readily converted to plastics, fuel, and other products. Three billion years ago oxygen was high entropy waste. When a resource is more valuable as a currency than as a stock, it should be used.

Biologists readily recognize that ecological overshoots are common in the environment, resulting in population boom and bust cycles, yet it seems this is something Homo sapiens are obligated to avoid (Hayes 2004). What is wrong with allowing a human boom and bust cycle? Is our species to exempt itself from normal ecological processes? It is naive to assume that the human populace is collectively sleepwalking toward the edge of ecological tragedy (Orr 2004; Law 3). First, there are significant questions as to whether this is actually occurring, and second, even if we are on the brink of disaster, backing away from the precipice may involve costs we are not willing to pay. Tradeoffs are inherent in any decision and this may be a case where the cure is worse than the disease. A preference for one pattern should not automatically be seen as an ecological necessity while an alternative preference is vilified. If the argument is that one strategy or another will "damage" the Earth (Lovejoy 2004), then we have two comments: (1) Are other natural boom and bust cycles also deleterious? (2) Even if we annihilate all compound organisms, won't there still be bacteria-the most dominant form of life on Earth? Ecosystem processes-reset by our actions or not-will continue.

\section{Conditions can Promote Creativity or Collapse}

We acknowledge the existence of many environmental problems that continue to compromise the health and 
welfare of ecological and human systems. Orr (2004; Law 3) states that in many cases the remedy is available but is not implemented. Oftentimes proposed remedies focus more on the symptoms than on the disease. A preponderance of environmental ills can be distilled into problems with property rights and limited access to capital. Bernstein (2004) posits that four conditions are necessary for rapid and sustained economic growth: effective property rights, scientific rationalism, capital markets, and speedy transportation of goods and communications. Property rights that are poorly defined, overtaxed, or under-enforced provide large incentive for overuse and waste. Further, if capital is not available for enterprises to develop and see their goods and services through to production, very little will happen. A lack of capital results in short-term decision making that discounts long-term processes. Without repeated application of the scientific model, critical system components are overlooked or misunderstood. Without communication and transportation, innovation and adaptation are retarded.

If problems that exist at the very heart of environmental issues are not addressed first, then any other proposed solution will fail. Contrary to Vitek (2004), conservation does not suffer from an excess of truth and a paucity of marketing. One cannot open a magazine, watch the news, or listen to the radio without being inundated with stories about environmental ills. There is a six-month waiting list for the Toyota Prius; people are not unaware. Perhaps we simply too often offer the wrong kind of truth - seemingly conflicted details buried in the jargon of academic journals rather than coherent and consistent insights into important processes.

\section{Rose-Colored Glasses and the Role of Science}

Environmentalism isn't the safety glasses in the toolbox (Vitek 2004); it is the tint of the lens. Conservationists and environmentalists have spent too much time and energy trying to "tap some deeper motivation than narrow self interest" (Orr 2004; Law 4). A far easier, less intrusive and more straightforward tool is available-incentives. Like all organisms, people respond to incentives. Trying to convince the general populace of the nobility of an action, the greater good to be gained, or the deep ecology of the movement is an inefficient use of time and energy. For most people, environmental self-actualization is just too far up Maslow's hierarchy of needs. Day-to-day decisions at least as basic as whether to eat, fill up the gas tank, or contribute to an emergency fund regularly trump saving the Atlantic tuna or an obscure tree frog. Incentives, on the other hand, affect day-to-day preferences and thus decisions. If you want people to purchase certified tuna or timber, make it cheaper than the alternative. If you want people to recycle newspapers, charge a deposit. $\mathrm{Al}$ though simpler said than done, this approach conforms much more consistently to ecological principles than do dictatorial or centrally planned methods. To be efficient we should advocate better systems, not just different outcomes.

Advocacy in a democracy is important, but it is not the role of science. Scientists should spend less energy publishing articles that promote activism and more energy investigating problems and coherently articulating answers to the questions that matter. Although science can inform us about what might be done to realize desired outcomes, it cannot tell us what outcomes should be pursued. Objectives such as limiting human growth or preserving Brazilian rainforests are not ecological imperatives; regardless of their implications, they are simply preferences. Conserving rainforests may mean less fuel for firewood and less agricultural land or more local employment and a preservation of a traditional culture. The degree of conservation should be based on the tradeoffs people are willing to make. Explicitly or implicitly forcing values on others by obscuring the distinction between facts and preferences may appear to be a viable avenue for achieving desired objectives, but it risks backlash and loss of credibility. Positive, proactive, and generative efforts offer far more potential for success than does restrictive regulatory activity reminiscent of the confined feeding of zoo animals. That, at the level of the impact, is the antithesis of ecological principles in action.

Don't accept ignorance or groupthink (Orr 2004) - use the tools and knowledge afforded by science to attack them systematically and aggressively.

\section{Literature Cited}

Bernstein, W. J. 2004. The birth of plenty: how the prosperity of the modern world was created. McGraw-Hill, New York.

Hayes, D. 2004. Deflating the ecological bubble. Conservation Biology 18:1461-1462

Lovejoy, T. E. 2004. Dreaming the impossible. Conservation Biology 18: 1465 .

Orr, D. W. 2004. Orr's laws. Conservation Biology 18:1457-1460.

Vitek, B. 2004. Abandon environmentalism for the sake of the revolution. Conservation Biology 18:1463-1464.

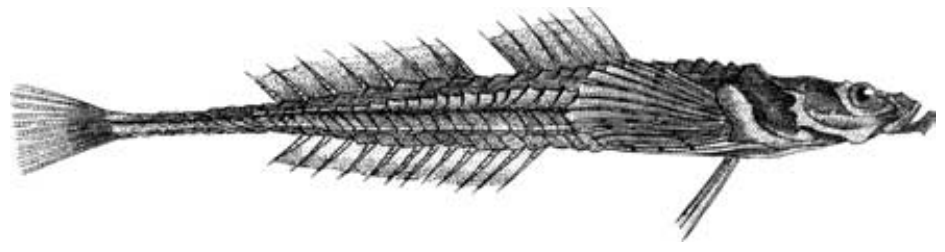

